\title{
A Descriptive Longitudinal Study of Chronic Pain Outcomes and Gender Differences in a Multidisciplinary Pain Management Centre
}

\author{
Teik G. Tay*, Andrea L. Willcocks, Judy F. Chen, Grazyna Jastrzab, Kok E. Khor \\ Department Pain Management, Level 1 McNevin-Dickson Building, Prince of Wales Hospital, Randwick, NSW \\ Australia \\ Email: ${ }^{*}$ teik.tay@sesiahs.health.nsw.gov.au
}

Received 16 January 2014; revised 18 February 2014; accepted 23 March 2014

Copyright $(\underset{2014}{ } 2 \mathrm{by}$ authors and Scientific Research Publishing Inc.

This work is licensed under the Creative Commons Attribution International License (CC BY). http://creativecommons.org/licenses/by/4.0/

\section{Open Access}

\section{Abstract}

Background: The long-term outcomes of patients with chronic pain treated in a multidisciplinary pain management center remain variable. Objective: This study aims to evaluate the changes in outcomes of patient's self-reported pain, psychosocial status, health related quality of life and gender differences following treatment in amultidisciplinary pain management centre. Design: A prospective longitudinal cross-sectional study uses questionnaires. Treatment Setting: A pragmatic and individualized patient centered approach in a tertiary level multidisciplinary pain management center. Subjects: Patients with chronic pain referred to the centre from 2004-2010. Outcome Measures: Pain Numerical Rating Scale (NRS), Pain Temporal Description (1 - 6), Pain SelfEfficacy Questionnaire (PSEQ), Depression Anxiety Stress Scales (DASS-21) and Short Form-36 (SF36). Follow-up questionnaires were sent at 6 and 12 months after initial assessment. Results: Mean duration of baseline chronic pain was 8.1 years and $61 \%$ of chronic pains were involving the musculoskeletal system. At 6 and 12 month follow-ups, 273 and 180 participants had been surveyed respectively. At 6-month follow-up, there were significant improvements on pain intensity (Cohen's $d=0.8$ ), pain self-efficacy (Cohen's $d=0.47$ ), depression and stress scores (Cohen's $d=$ 0.16 ) and six out of eight domains of SF-36 (Cohen's $d=0.2-0.4$ ). At 12-month follow-up, improvements were maintained on pain intensity, self-efficacy and three out of eight domains of SF-36. There were distinctive pre- and post-treatment gender differences in these outcomes and overall females showed better short- and long-term outcomes than males. Conclusion: Multidisciplinary pain management using an individualized patient centered approach remains an effective treatment for chronic pain in both the short- ( 6 month) and long-term (12 month). The distinctive pre- and post-treatment gender differences particularly in the psychological outcomes, suggest that it may be beneficial to further delineate and better manage vulnerable patient subgroups.

${ }^{*}$ Corresponding author.

How to cite this paper: Tay, T.G., et al. (2014) A Descriptive Longitudinal Study of Chronic Pain Outcomes and Gender Differences in a Multidisciplinary Pain Management Centre. Pain Studies and Treatment, 2, 56-69.

http://dx.doi.org/10.4236/pst.2014.22010 


\section{Keywords}

\section{Multidisciplinary, Pain Management Center, Quality of Life, Chronic Pain, Self-Efficacy, Gender, Long-Term Outcome}

\section{Introduction}

Chronic pain is a common disorder associated with significant psychological comorbidity and functional disability. The epidemiological study has reported approximately $20 \%$ of the adult Australian population have chronic pain and one third of people with chronic pain have high levels of pain related disability [1] [2]. Chronic pain often causes psychological distress such as depression, anxiety, poor self-efficacy and health-related quality of life and has negative social ramifications such as unemployment, loss of working days and reduced job effectiveness [3] [4]. Since chronic pain is complex and multi-dimensional in its nature, the current model of chronic pain management is characterized by multi-faceted medical, physical and psychological interventions by a multidisciplinary team, with an emphasis on improving pain coping, acceptance, self-management to improve psychological factors, physical functioning and quality of life [5]-[7]. Systematic reviews and meta-analyses have found that intensive multidisciplinary pain management programs are more effective than waiting lists, no treatment, or unidisciplinary treatment [8]-[11].

Over the past two decades, studies have shown that outpatient-based chronic pain management programs or interventions have consistently provided modest improvements in pain report, physical and emotional functioning in patients with chronic pain [12] [13]. Recently, Dysvik et al. [14] reported that multidisciplinary pain management led to improvements in pain intensity and health-related quality of life (HRQoL) at both 6- and 12month follow-ups. In contrast, Baranoff et al. [15] reported no significant improvement in pain intensity or anxiety at a 6-month follow-up but showed improvements on other psychosocial outcomes such as depression, stress and disability. Moreover, some studies suggest that there are gender differences in the long-term effects of multidisciplinary interventions as males appear to have better outcomes, for both pain and psychosocial status, at a 6-month follow-up compared to females [16] [17]. In contrast, other studies have reported better post-treatment occupational outcomes for females with fewer absent days from work and improved role physical and social functioning in fibromyalgia patients [18] [19].

There is a paucity of data on the long-term clinical course and outcomes of a heterogeneous sample of patients with chronic pain even though this is typically the focus of most outpatient-based multidisciplinary pain management programs. The current study had two primary aims: first, to evaluate overall outcomes in a cohort of patients with chronic pain at 6- and 12-month follow-up assessments. To do this, outcomes were evaluated using standardized, validated questionnaires for pain [pain intensity (NRS) and pain temporal characteristic] and psychosocial measures [PSEQ, DASS-21] and HRQoL measure [SF-36]. Secondly, we examined longitudinal gender differences in pain intensity and psychosocial outcomes.

\section{Method}

\subsection{Participants}

Baseline data were obtained from patients with chronic pain who were referred to the Pain Management Clinic, Prince of Wales Hospital, Randwick, NSW, Australia, from January 2004 to December $2010(n=906)$. Patients with any type of pain lasting for at least 3 months and referred by their general practitioner or attending specialist were accepted in to the Clinic. Consent was also obtained from patients for the purpose of data collection. Retrospective ethics approval was obtained from the South Eastern Sydney Local Health District-Northern Sector Human Research Ethics Committee.

\subsection{Study Design}

The present study was a prospective longitudinal review of chronic pain outcomes for patients who were referred to and treated in a tertiary hospital-based pain management center with 6 and 12 month follow-ups. Questionnaires were sent out by post to the patients' addresses and no reminder mails were sent. Baseline question- 
naires were completed before initial assessment, but completion of the 6 and 12-month follow-up questionnaires were entirely voluntary.

\subsection{Outcome Measures}

Data on demographics, pain locations, physiological systems, etiology of pain, psychosocial parameters-marital, country background, language, work and compensation status were collected. Outcome measurements of pain intensity rating (NRS 0-10), pain temporal characteristics statements (1 - 6), Pain Self-Efficacy (PSEQ), Depression Anxiety Stress Scales (DASS-21) and HRQoL (Medical Outcome Study Short Form-36) were obtained at baseline, 6 and 12 month after the first pain assessment.

Pain intensity-Numerical Rating Scale (NRS) 0 - 10

Pain intensity is self-reported by patient using the numerical rating scales (NRS) of 0 - 10 . The score of 0 means no pain, 2-mild pain, 4-moderate pain, 6-severe pain, 8-very severe pain and 10-the worst pain possible.

Pain Temporal Characteristic Statements (1 - 6)

Pain temporal characteristic statement is a single item questionnaire used to describe pain temporal characteristic over time. It has 6 descriptive categories: Score of 1-Always present, always the same intensity, 2-Always present, intensity varies, 3-Usually present, but have short periods without pain, 4-Often present, but have pain free periods lasting up to several hours, 5-Occasionally present for brief periods, but not every day, and 6-Rarely present-have pain episodes every now and then, with days/weeks in between.

Pain Self-Efficacy Questionnaires (PSEQ) (0 - 60)

The Pain Self-Efficacy Questionnaire (PSEQ) is based on Bandura's concept of efficacy expectation determine how much efforts people and how long they will persist in the face of obstacles and aversive experiences [20] [21]. PSEQ has 10-items which measure the strength and generality of a patient's belief about his/her ability to accomplish a range of specified daily activities. It has high internal consistency (Cronbach's alpha coefficient $=0.92$ ) and strong validity [22]. Patient with high self-efficacy is correlated to have higher pain thresholds and tolerance in experimental induced pain than those with low self-efficacy [23].

Depression Anxiety and Stress Scales (DASS-21)

The DASS-21 has 21 items, which measure psychological mood states of depression, anxiety and stress concurrently. It has a Z score normogram enable the item score to be transformed into severity scale on each mood state. In the category of depression: Score 0 - 9 means normal, 10-13 (mildly depressed), 14 - 20 (moderately depressed), 21 - 27 (severely depressed), 28 - 42 (extremely depressed); Category of anxiety-score 0 - 7 (normal), 8 -10 (mild), 11 - 14 (moderate), 15 - 19 (severe), 20 - 42 (extremely severe); Category of stress-score 0 14 (normal), 15 - 18 (mild), 19 - 26 (moderate), 27 - 34 (severe), 35 - 42 (extremely severe). The validity, reliability and sensitivity are well established in reflecting the psychological states of patient. Within the Australian population there is evidence that all three of the DASS-21 subscales are appropriate and informative for groups of chronic pain patients [24] [25]. However, there is evidence that an aggregate score of negative affect is not appropriate [25] [26] and this is not examined here.

Short Form-36 (SF-36)

The short form-36 (SF-36) is a general health related questionnaire with 36-items (Ware, 1992). Since its development, the SF-36 has been used extensively in research as a measure of health-related quality of life. The questionnaire covers 8 important domains related to physical and mental health over the past month. They assess health related concepts including general health, physical functioning, role functioning-physical, bodily pain, vitality, social functioning, role functioning-emotional, and mental health. The score of each domain ranges from 0 - 100, with higher scores indicating better quality of life. Scores of bodily pain overlap with the measure of pain intensity. The scores of physical function and role physical domain measure the quality of physical health. The scores of mental health and role emotion domains reflect quality of mental health.

\subsection{Procedure}

The patient with chronic pain $>6$ months were referred from their primary care physician or specialist and a set of baseline questionnaires were sent to the addresses of the patient before the first appointment was arranged. Selected group of chronic pain patient with a widespread area or complex pain associated with poor pain selfefficacy, mood disturbances and functional disability were given an initial multidisciplinary pain assessment. 
Patient was offered treatment modality based on individualized patient-centred approach to the pain diagnosis, patient's expectations and consensus opinion of the multidisciplinary team members during a case conference. The multidisciplinary pain assessment involved a specialist pain medicine physician, clinical psychologist and physiotherapist evaluations over a period of 3 hours. Patient who were not triaged for multidisciplinary pain assessment were seen by the pain physician who would initiate individualized patient-centred treatment targeted to their specific pain condition or referred to other members of the multidisciplinary team (e.g. psychological or physical therapy) for specific interventions.

Individualized patient-centred pain management was initiated according to the treatment plan established after the first clinic assessment. The essential components in our multidisciplinary pain management treatments, which is similar to that proposed by Okifuji et al. [27] includes medical interventions (e.g., pharmacological, diagnostic/therapeutic nerve blocks or injections, transcutaneous electrical nerve stimulator), psychological interventions (e.g., cognitive behavioral therapy, pain coping skills training, pain education) and physical interventions (e.g., physical reactivation, graded exposure exercise program, hydrotherapy). Main proportion of patient had a combination of treatments, which progressed concurrently for a specific period. Medical follow-ups were conducted as frequently as deemed necessary and usually involved various evidence-based pharmacological therapies such as simple analgesics, adjuvant analgesics (e.g., tricyclic antidepressants, gabapentinoids, serotonin noradrenaline re-uptake inhibitors) and when required, opioid analgesics of various strengths. Interventional pain therapies were initiated only for patient with refractory pain, who was debilitating and unresponsive to non-invasive therapies. This commonly involved focal injection of local anaesthetics, steroids or application of radiofrequency lesioning/neurotomies techniques to specifican atomical sites or neural structures. Centrally acting analgesic infusions (e.g., ketamine, lignocaine) and advanced implantable pain therapies (e.g., spinal cord and peripheral nerve stimulators, intrathecal drug infusion pumps). Lastly, the multidisciplinary pain management also involved other medicalor allied health disciplines in collaboration with primary care physician, such as liaison psychiatry, addiction medicine, rehabilitation medicine, palliative medicine, occupational therapy and social work.

\section{Statistical Analysis}

Data were analyzed and compared using the SPSS-12.0 software. ANOVA and Kruskal-Wallis tests were used to compare the baseline pain and psychosocial outcomes between the responders and non-responders. "Responders" were identified as those who responded to the outcome questionnaires on the baseline, and 6- or 12month follow up. The patients who responded only to the baseline questionnaires but not the 6- or 12-month follow up were identified as “non-responders”. Responders' longitudinal time change in pain and psychosocial outcomes were compared using parametric ANOVA and non-parametric Kruskal-Wallis tests and the magnitude of change were measured using the Cohen's d effect size [28]. The effect size is calculated by the difference between the means divided by the standard deviation of the pre-change value. An effect size of 1.0 is equal to the change of 1 standard deviation of pre-change value. A linear mixed model approach was chosen to address the changes in outcome measures over time for the sample. A linear mixed model is appropriate for use with an unbalanced design, missing data, and repeated observations that are not independent (i.e. correlated) as is the case with longitudinal data [29] [30]. To examine changes in outcome measures over time each measure was entered as the dependent variable (e.g. pain intensity, self-efficacy) and the fixed effect of time (0, 6 and 12 months) was examined. To examine gender differences, this same model was applied with the addition of the interaction between gender and time (gender*time) entered into fixed effects. The resulting output gave a difference score for each scale (i.e. change between 0 and 6 months) and a 95\% confidence interval for this difference, which indicated the magnitude of each effect. The relationship between the change in pain intensity with other changes in pain outcome and demographic data were analysed with Pearson's correlation and step-wise linear regression analysis. Repeated measure multivariate analysis of variance (MANOVA) was used to evaluate the gender difference in the pain outcomes at baseline, 6 and 12 month after pain management. $p$ value was set at $<0.05$.

\section{Results}

From 2004-2010, a total of 906 participants completed the mandatory baseline questionnaires and 273 (30\%) and 180 (20\%) responded to the 6- and 12-month follow-ups, respectively. Table 1 shows there were no signif- 
Table 1. Baseline measures for responders and non-responders.

\begin{tabular}{cccc}
\hline & Responders (N = 273) & Non-responders $(\mathrm{N}=633)$ & P values (Sig. $\left.<0.05^{*}\right)$ \\
\hline Pain intensity (NRS 0 - 10) & $7.01(1.96)$ & $7.04(1.99)$ & 0.83 \\
PSEQ (0 - 60) & $20.2(13.1)$ & $19.8(13.8)$ & 0.70 \\
DASS-21 subscales (0 - 42) & & $17.1(13.3)$ & 0.69 \\
Depression & $16.7(12.3)$ & $12.0(10.8)$ & 0.95 \\
Anxiety & $11.9(10.3)$ & $17.4(13.1)$ & 0.62 \\
Stress & $17.8(11.6)$ & & 0.33 \\
QOL-SF-36 subscales & & $20.4(22.7)$ & 0.88 \\
General health & $38.7(22.7)$ & $25.3(18.6)$ & 0.61 \\
Bodily pain & $25.4(17.9)$ & $35.3(24.8)$ & 0.17 \\
Physical function & $36.2(24.9)$ & $37.8(28 . .6)$ & 0.97 \\
Social function & $40.9(27.8)$ & $38.8(43.3)$ & 0.78 \\
Role emotional & $38.9(43.1)$ & $15.7(29.7)$ & 0.32 \\
Role physical & $15.1(31.9)$ & $29.9(17.4)$ & 0.21 \\
Vitality & $31.2(17.8)$ & $50.4(19.1)$ & \\
Mental health & $52.6(22.5)$ & & \\
\hline
\end{tabular}

Abbreviations: NRS $=$ Numerical Rating Scale, PSEQ $=$ Pain Self-efficacy Questionnaires, DASS-21 $=$ Depression Anxiety Stress Scale-21 items, QOL-SF 36 = Quality of Life-Short Form 36 items Questionnaires.

icant differences in the baseline outcomes between the responders and non-responders of the initial questionnaires.

(1) Demographics and Multi-Axial Systems Description of Chronic Pain Characteristics

Demographics and psychosocial factors of chronic pain patients are described in Table 2. The mean age of patients was 58.6 years (Range 18 - 102 years, SD 16.8) and there were more females ( $n=568$; 63\%) compared to males $(n=337 ; 37 \%)$.

Table 3 shows baseline mean pain score was 7.1 (SD 2.0) and mean duration of chronic pain was 8.1 years (SD 10.8). The most common region of pain complaint was in lower back (37.2\%), followed by lower limbs (18.8\%), shoulder and upper limbs (13.7\%) and pain more than 3 sites (8.2\%). Almost two thirds of cases were involving the musculoskeletal/connective tissue system (61.0\%) and less than one third were neurological in nature (26.8\%). The most common nominated cause of chronic pain was degenerative or mechanical (39.7\%) followed by post-traumatic or post-operative (30.2\%).

(2) Pain, Psychological Functions and Health-Related Quality of Life Outcomes: Baseline, 6- and 12-Month

Table 4 shows mean values of psychosocial and pain measures at baseline, 6 and 12 month follow-ups. Table 5 shows the results of linear mixed model analysis on changes between baseline and follow-ups on psychosocial and pain measures.

(i) Pain Intensity [Numerical Rating Scale] (0 - 10)

At initial referral, the mean pain intensity was $7.1(\mathrm{SD} 2.0,95 \% \mathrm{CI}=3.18$ - 11.02) whereas the mean intensity was $5.5(\mathrm{SD} 2.2,95 \% \mathrm{CI}=1.58-9.42)$ and $5.4(\mathrm{SD} 2.3,95 \% \mathrm{CI}=0.89-9.91)$ at 6 and 12 months, respectively. There was a significant reduction in mean pain intensity after 6 months (Cohen's d size $=0.8, \mathrm{~b}=-2.0, \mathrm{P}<$ 0.001 ) and this improvement was maintained at 12 months (Cohen's $d$ size $=0.85, \mathrm{~b}=-1.6, \mathrm{P}<0.001$ ).

(ii) Pain Self-Efficacy Scores [PSEQ] (0 - 60)

The mean self-efficacy PSEQ score at baseline was 19.7 (SD 13.4); was 26.0 at 6 months (SD 14.5); and at 12 month was 24.7 (SD 14.8). There was a significant increase in mean self-efficacy score after 6 months (Cohen's $\mathrm{d}$ size $=0.47, \mathrm{~b}=6.7, \mathrm{P}<0.001$ ) and this improvement was maintained at 12 months (Cohen's $\mathrm{d}$ size $=0.37, \mathrm{~b}=$ $5.2, \mathrm{P}<0.001)$. 
Table 2. Demographics and psychosocial factors at baseline, 6- and 12-month follow-up (N [\%] unless noted).

\begin{tabular}{|c|c|c|c|}
\hline & Baseline $(\mathrm{N}=906)$ & $\begin{array}{c}\text { 6-month Follow-up } \\
\text { (N = 273) }\end{array}$ & $\begin{array}{l}\text { 12-month Follow-up } \\
\text { (N = 180) }\end{array}$ \\
\hline Age (years), mean (SD) & $58.6(16.8)$ & $62.5(15.4)$ & $63.2(15.0)$ \\
\hline $\begin{array}{c}\text { Gender } \\
\text { Male } \\
\text { Female }\end{array}$ & $\begin{array}{l}337(37.2) \\
568(62.8)\end{array}$ & $\begin{array}{l}109(39.9) \\
164(60.1)\end{array}$ & $\begin{array}{c}65(36.1) \\
115(63.9)\end{array}$ \\
\hline $\begin{array}{c}\text { Marital status } \\
\text { Married } \\
\text { Never married } \\
\text { Widowed/divorced/separated }\end{array}$ & $\begin{array}{l}345(38.2) \\
220(24.4) \\
337(37.4)\end{array}$ & $\begin{array}{c}118(43.2) \\
109(40.0) \\
46(16.8)\end{array}$ & $\begin{array}{l}71(39.4) \\
34(18.9) \\
75(41.6)\end{array}$ \\
\hline $\begin{array}{c}\text { Country Born } \\
\text { Australian born } \\
\text { Overseas born }\end{array}$ & $\begin{array}{l}486(53.6) \\
383(42.3)\end{array}$ & $\begin{array}{l}141(51.6) \\
120(44.0)\end{array}$ & $\begin{array}{l}100(55.6) \\
71(39.4)\end{array}$ \\
\hline $\begin{array}{l}\text { English Proficiency } \\
\text { Very well or well } \\
\text { Not well } \\
\text { Not at all }\end{array}$ & $\begin{array}{c}785(86.6) \\
95(10.5) \\
15(1.7)\end{array}$ & $\begin{array}{c}233(85.3) \\
34(12.5) \\
5(1.8)\end{array}$ & $\begin{array}{c}161(89.4) \\
17(9.4) \\
1(0.6)\end{array}$ \\
\hline $\begin{array}{l}\text { Education Level } \\
\text { Still at school } \\
\text { Did not go to school } \\
\text { Year } 8 \text { or below } \\
\text { Year } 9-12 \text { or above }\end{array}$ & $\begin{array}{c}2(0.2) \\
22(2.5) \\
147(16.9) \\
701(80.5)\end{array}$ & $\begin{array}{c}0(0) \\
8(3) \\
60(22.8) \\
195(74.2)\end{array}$ & $\begin{array}{c}0(0) \\
3(1.7) \\
39(22.5) \\
131(75.8)\end{array}$ \\
\hline Unemployment Duration (years), mean (SD) & $7.1(7.1)$ & $8.0(6.9)$ & $8.7(6.9)$ \\
\hline $\begin{array}{c}\text { Occupation/Social Status } \\
\text { Full-time work } \\
\text { Part-time work } \\
\text { Voluntary work } \\
\text { Home duties } \\
\text { Retired } \\
\text { Student } \\
\text { Unemployed (due to pain) } \\
\text { Retraining } \\
\text { Unemployed (other reason) }\end{array}$ & $\begin{array}{c}109(12.4) \\
78(8.9) \\
9(1) \\
82(9.3) \\
276(31.3) \\
21(2.4) \\
219(24.9) \\
4(0.5) \\
83(9.4)\end{array}$ & $\begin{array}{c}23(9) \\
26(10.2) \\
4(1.6) \\
39(15.2) \\
89(34.8) \\
4(1.6) \\
48(18.8) \\
4(1.6) \\
19(7.4)\end{array}$ & $\begin{array}{c}8(4.9) \\
13(7.9) \\
3(1.8) \\
18(11) \\
76(46.3) \\
1(0.6) \\
35(21.3) \\
1(0.6) \\
9(5.5)\end{array}$ \\
\hline $\begin{array}{l}\text { Compensation } \\
\text { Worker's compensation } \\
\text { Third party insurance case } \\
\text { Some other legal case } \\
\text { None of the above }\end{array}$ & $\begin{array}{c}88(10.2) \\
24(2.8) \\
11(1.3) \\
741(85.8)\end{array}$ & $\begin{array}{c}21(8) \\
5(1.9) \\
2(0.8) \\
235(89.4)\end{array}$ & $\begin{array}{c}10(5.7) \\
5(2.9) \\
0(0) \\
159(91.4)\end{array}$ \\
\hline
\end{tabular}

(iii) Depression Anxiety Stress Scales [DASS-21] (0 - 42)

The baseline mean DASS depression score was 16.9 (SD 12.7); at 6 months was 14.8 (SD 11.7) and at 12 months was 15.7 (SD 11.9). The baseline mean DASS anxiety score was 12.1 (SD 10.6); at 6 months was 12.1 (SD 10.3) and at 12 months was 12.1 (SD 9.9). The baseline mean DASS stress score was 17.8 (SD 11.9 ); at 6 months was 15.8 (SD 11.1), and at 12 months was 16.7 (SD 11.8). There was a significant improvement in mean DASS depression and stress scores after 6 months (Depression: Cohen's d size $=0.16, \mathrm{~b}=-2.4, \mathrm{P}<0.001$; Stress: Cohen's d size $=0.16, \mathrm{~b}=-2.3, \mathrm{P}<0.001)$. These improvements were not maintained at 12 months (Depression: $\mathrm{b}=-1.7, \mathrm{P}=0.54$; Stress: $\mathrm{b}=-1.3, \mathrm{P}=0.13$ ). Importantly, there was no improvement in anxiety scores at $6(\mathrm{~b}=-0.08, \mathrm{P}=0.89)$ or 12 months $(\mathrm{b}=-0.3, \mathrm{P}=0.65)$.

(iv) Health Related Quality of Life Short Form-36 [SF-36] (0 - 100)

Statistical significant differences were detected on six out of eight domains (see Table 5) (except general health (GH) and social function (SF)) of health-related quality of life (SF-36) scores, after 6 month post-referral. The Cohen's d effect sizes for these changes were small $<0.4$. Sustainable change in the domains of role physical (RP), bodily pain (BP) and social functioning (SF) were noted after 12 months post-referral.

(v) Correlation and Regression Analysis of Chronic Pain and Psychosocial Factors

Pearson's correlation was utilized to examine the correlation between the pain intensity and the psychosocial 
Table 3. Summary of pain related characteristics of chronic pain patients referred to out-patient based pain management.

\begin{tabular}{|c|c|}
\hline & Sample (N [\%] unless noted) \\
\hline Duration of pain (years), (mean [SD]) & $8.1(10.8)$ \\
\hline Pain intensity (mean [SD]) & $7.1(2.0)$ \\
\hline \multicolumn{2}{|l|}{ Regions of chronic pain } \\
\hline Head, face, mouth & $55(6.4)$ \\
\hline Cervical region & $64(7.5)$ \\
\hline Upper shoulder \& upper limbs & $117(13.7)$ \\
\hline Thoracic region & $24(2.8)$ \\
\hline Abdominal region & $29(3.4)$ \\
\hline Lower back, lumbar to соссух & $318(37.2)$ \\
\hline Lower limbs & $161(18.8)$ \\
\hline Pelvic region & $15(1.7)$ \\
\hline Anal, perineal \& genital region & $2(0.2)$ \\
\hline More than three sites & $70(8.2)$ \\
\hline \multicolumn{2}{|l|}{ Body systems } \\
\hline Nervous (physical) & $154(26.8)$ \\
\hline Nervous (psychological/social) & $25(4.4)$ \\
\hline Respiratory \& cardiovascular & $6(1.0)$ \\
\hline Musculoskeletal/connective tissue & $351(61)$ \\
\hline Cutaneous/subcutaneous/gland & $1(0.17)$ \\
\hline Gastro-intestinal & $9(1.6)$ \\
\hline Genito-urinary & $7(1.2)$ \\
\hline Other organs or viscera & $1(0.17)$ \\
\hline More than one system & $20(3.5)$ \\
\hline Unknown & $1(0.17)$ \\
\hline \multicolumn{2}{|l|}{ Aetiologies } \\
\hline Genetic or congenital & $54(9.5)$ \\
\hline Trauma/operation/burns & $172(30.2)$ \\
\hline Infective & $6(1.0)$ \\
\hline Inflammatory/immune reactions & $44(7.7)$ \\
\hline Neoplasm & $3(0.53)$ \\
\hline Toxic/metabolic & $8(1.4)$ \\
\hline Degenerative/mechanical & 226 (39.65) \\
\hline Dysfunctional (psycho-physiologic) & $25(4.4)$ \\
\hline Psychological (no physical cause) & $28(4.9)$ \\
\hline Unknown & $4(0.7)$ \\
\hline
\end{tabular}


Table 4. Mean (SD) values of pain and psychosocial outcomes at baseline, 6- and 12-month.

\begin{tabular}{cccc}
\hline & Baseline $(\mathrm{N}=906)$ & 6 month $(\mathrm{N}=273)$ & 12 month $(\mathrm{N}=180)$ \\
\hline Duration of pain (years), (mean [SD]) & $8.1(10.8)$ & $7.3(10.8)$ & $9.1(11.7)$ \\
Pain intensity & $7.1(2.0)$ & $5.5(2.2)$ & $5.4(2.3)$ \\
Temporal statements & $2.2(0.9)$ & $2.6(1.2)$ & $2.6(1.2)$ \\
PSEQ & $19.7(13.4)$ & $26.0(14.5)$ & $24.7(14.8)$ \\
DASS subscales & & & \\
Depression & $16.9(12.6)$ & $14.7(11.7)$ & $15.8(11.9)$ \\
Anxiety & $12.1(10.6)$ & $12.1(10.3)$ & $16.7(11.8)$ \\
Stress & $17.8(12.0)$ & $15.9(11.2)$ & $36.9(22.0)$ \\
SF-36 subscales & & & $39.2(21.0)$ \\
General health & $39.7(22.6)$ & $40.3(23.5)$ & $34.8(25.6)$ \\
Bodily pain & $29.5(18.8)$ & $37.1(19.5)$ & $45.3(30.2)$ \\
Physical function & $34.6(25.1)$ & $38.8(26.5)$ & $46.9(42.8)$ \\
Social function & $38.5(27.4)$ & $45.8(26.8)$ & $24.0(34.9)$ \\
Role emotional & $40.4(43.2)$ & $47.8(44.6)$ & $54.1(20.3)$ \\
Role physical & $16.8(30.7)$ & $27.4(35.8)$ & \\
Vitality & $29.5(15.8)$ & $56.3(16.6)$ & \\
Mental health & $51.5(21.1)$ & & \\
\hline
\end{tabular}

Table 5. Pain and psychosocial outcomes at 6 and 12 month follow-up relative to baseline.

\begin{tabular}{|c|c|c|c|c|}
\hline \multirow[t]{2}{*}{ Measure } & \multicolumn{2}{|c|}{ Pre vs $6 \mathrm{mth}$} & \multicolumn{2}{|c|}{ Pre vs 12 mth } \\
\hline & $b(95 \% \mathrm{CI})$ & P-value & $b(95 \% \mathrm{CI})$ & P-value \\
\hline Pain intensity & $-2.0(-2.2,-1.80)$ & $<0.001^{*}$ & $-1.62(-1.94,-1.30)$ & $<0.001^{*}$ \\
\hline \multicolumn{5}{|l|}{ DASS-21 } \\
\hline Depression & $-2.43(-3.70,-1.15)$ & $<0.001^{*}$ & $-1.74(-3.51,0.03)$ & 0.54 \\
\hline Anxiety & $-0.08(-1.16,1.00)$ & 0.89 & $-0.33(-1.77,1.11)$ & 0.65 \\
\hline Stress & $-2.34(-3.57,-1.11)$ & $<0.001^{*}$ & $-1.32(-3.04,0.40)$ & 0.13 \\
\hline PSEQ & $6.66(4.70,8.62)$ & $<0.001^{*}$ & $5.23(2.89,7.58)$ & $<0.001^{*}$ \\
\hline \multicolumn{5}{|l|}{ SF-36 } \\
\hline General health & $1.98(-0.40,4.34)$ & 0.10 & $-0.30(-3.70,3.08)$ & 0.86 \\
\hline Physical function & $4.26(1.54,6.99)$ & $0.02^{*}$ & $1.91(-1.99,5.81)$ & 0.34 \\
\hline Mental health & $6.14(3.64,8.63)$ & $<0.001^{*}$ & $2.94(-0.50,6.37)$ & 0.094 \\
\hline Role emotional & $7.59(1.37,13.82)$ & $0.017^{*}$ & $7.97(-0.40,16.34)$ & 0.062 \\
\hline Role physical & $8.52(3.85,13.20)$ & $<0.001^{*}$ & $8.67(2.89,14.45)$ & $0.003^{*}$ \\
\hline Bodily pain & $9.68(7.28,12.08)$ & $<0.001^{*}$ & $11.39(8.19,14.60)$ & $<0.001^{*}$ \\
\hline Vitality & $5.69(3.63,7.74)$ & $<0.001^{*}$ & $2.10(-0.63,4.85)$ & 0.13 \\
\hline Social function & $12.75(-45.90,71.40)$ & 0.65 & $72.47(7.23,137.72)$ & $0.032^{*}$ \\
\hline
\end{tabular}


factors of chronic pain patients. Correlations between the country of birth level of English proficiency and work status with the pain intensity $(\mathrm{p}<0.001$ ) were detected. A step-wise linear regression analysis was performed to determine pre-treatment pain and psychosocial functions that contributed to the change in the pain intensity over time. Regression analysis detected $47 \%$ of variance $\left(\mathrm{R}^{2}=0.47 \mathrm{df} 16, \mathrm{~F} 57.2\right)$ of pain intensity accounted by the predictive factor of pain self-efficacy (B-0.032, Sig. 0.000); pain temporal characteristic statement (B-0.609, Sig. 0.000), SF-36-Bodily Pain (B-0.016, Sig. 0.000) and time referral factor (B-0.464, Sig 0.000).

(3) Gender Differences in Pain and Psychosocial Functional Outcomes: Baseline, 6- and 12-month

The gender differences in pain, psychological functions (DASS), self-efficacy (PSEQ) and quality of life (SF36) outcome were described in Table 6. There was a significant improvement in scores on the bodily pain domain of SF-36 at 6-and 12-month for both males (6mth: $\mathrm{b}=8.0, \mathrm{P}<0.001 ; 12 \mathrm{mth}: \mathrm{b}=11.7, \mathrm{P}<0.001)$ and females (6-month: $\mathrm{b}=10.6, \mathrm{P}<0.001 ; 12$-month: $\mathrm{b}=10.9, \mathrm{P}<0.001$ ) (Table 6).

There was a significant reduction in pain intensity at 6 -month for both males $(\mathrm{b}=-1.7, \mathrm{P}<0.001)$ and females $(\mathrm{b}=-2.2, \mathrm{P}<0.001$ ) and this was maintained at 12-month (Males: $\mathrm{b}=-1.7, \mathrm{P}=0.016$; Females: $\mathrm{b}=-1.7$, $\mathrm{P}=0.007$ ) as illustrated in Figure 1. At 6- and 12-month follow-up, After Both genders' pain intensity reduced without significant difference between groups over time.

There was significant improvement in pain self-efficacy scores at 6-month for both males $(b=6.3, P<0.001)$ and females ( $\mathrm{b}=7.2, \mathrm{P}<0.001)$ (Figure 2(A)). This improvement in PSEQ was maintained at 12-month for females $(\mathrm{b}=5.8, \mathrm{P}<0.001)$ but not males $(\mathrm{b}=3.5, \mathrm{P}=0.07)$. There was also a significant improvement in scores on the depression and stress subscales of the DASS-21 at 6-month for females (Depression: $\mathrm{b}=-3.3, \mathrm{P}<0.001$ : Stress: $\mathrm{b}=-3.2, \mathrm{P}<0.001$ ) but this improvement was not maintained at 12 -month (Depression: $\mathrm{b}=-2.0, \mathrm{P}=$ 0.08; Stress: $b=-2.0, P=0.057$ ) (Figure 2(B) and Figure 2(C)).

In contrast, males showed no improvement on the depression or stress subscales at either 6- or 12-month and neither gender had improvements on the anxiety subscale at any point (Figure 2(D)).

\section{Discussions}

This study had evaluated the long-term course of a heterogeneous patient group with chronic pain that received individualized pain management treatment in a tertiary hospital-based multidisciplinary center. Our results demonstrated that chronic pain patients showed both short- (6 months) and long-term (12 months) improvements in pain, self-efficacy, psychological function and health-related quality of life. The improvements in pain intensity and self-efficacy were sustained at 12 months. Our results are consistent with the recent finding of long-term positive outcomes in pain intensity and HRQoL measure at both 6 and 12 month follow-ups when patients receive intensive CBT for chronic pain [14].

Table 6. Gender differences in pain and psychosocial outcomes at initial assessment compared to 6- and 12-month follow-ups.

\begin{tabular}{|c|c|c|c|c|c|c|c|c|}
\hline \multirow[b]{3}{*}{ Measure } & \multicolumn{4}{|c|}{ Pre vs 6 month } & \multicolumn{4}{|c|}{ Pre vs 12 month } \\
\hline & \multicolumn{2}{|l|}{ Males } & \multicolumn{2}{|l|}{ Females } & \multicolumn{2}{|l|}{ Males } & \multicolumn{2}{|l|}{ Females } \\
\hline & $b(95 \% \mathrm{CI})$ & $P$-value & $b(95 \% \mathrm{CI})$ & P-value & $b(95 \% \mathrm{CI})$ & P-value & $b(95 \% \mathrm{CI})$ & P-value \\
\hline Pain intensity & $-1.7(-2.0,-1.3)$ & $<0.001^{*}$ & $-2.2(-2.5,-1.9)$ & $<0.001^{*}$ & $-1.7(-2.8,-0.6)$ & $0.016^{*}$ & $-1.7(-2.5,-0.9)$ & $0.007^{*}$ \\
\hline \multicolumn{9}{|l|}{ DASS-21 } \\
\hline Depression & $-1.2(-3.2,0.7)$ & 0.2 & $-3.3(-4.9,-1.6)$ & $<0.001^{*}$ & $-1.2(-4.1,1.8)$ & 0.4 & $-2.0(-4.2,0.2)$ & 0.08 \\
\hline Anxiety & $1.2(-0.5,2.8)$ & 0.16 & $-0.9(-2.3,0.5)$ & 0.19 & $1.3(-1.0,3.6)$ & 0.28 & $-1.2(-2.9,0.5)$ & 0.17 \\
\hline Stress & $-1.2(-3.1,0.7)$ & 0.2 & $-3.2(-4.7,-1.5)$ & $<0.001^{*}$ & $0.0(-2.8,2.8)$ & 0.9 & $-2.0(-4.2,0.1)$ & 0.057 \\
\hline PSEQ & $6.3(3.6,8.7)$ & $<0.001^{*}$ & $7.2(4.9,9.4)$ & $<0.001^{*}$ & $3.5(-0.3,7.2)$ & 0.07 & $5.8(3.0,8.6)$ & $<0.001^{*}$ \\
\hline \multicolumn{9}{|l|}{ SF-36 } \\
\hline Role physical & $8.9(0.9,16.9)$ & $0.03^{*}$ & $8.3(1.6,14.9)$ & $0.015^{*}$ & $4.3(-6.3,14.9)$ & 0.8 & $10.8(3.1,18.4)$ & $0.006^{*}$ \\
\hline Bodily pain & $8.0(4.2,11.9)$ & $<0.001^{*}$ & $10.6(7.4,13.7)$ & $<0.001^{*}$ & $11.7(6.2,17.2)$ & $<0.001^{*}$ & $10.9(6.9,14.9)$ & $<0.001^{*}$ \\
\hline Vitality & $5.5(2.3,8.8)$ & $0.001^{*}$ & $5.7(3.0,8.4)$ & $<0.001^{*}$ & $0.5(-4.1,5.2)$ & 0.8 & $2.9(-0.5,6.3)$ & 0.09 \\
\hline
\end{tabular}




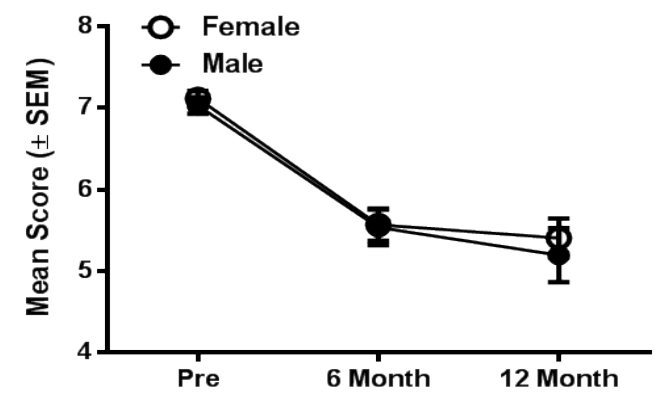

Figure 1. The mean $( \pm$ SEM) self-reported pain intensity scores for males and females at initial assessment, 6- and 12-month follow-up.
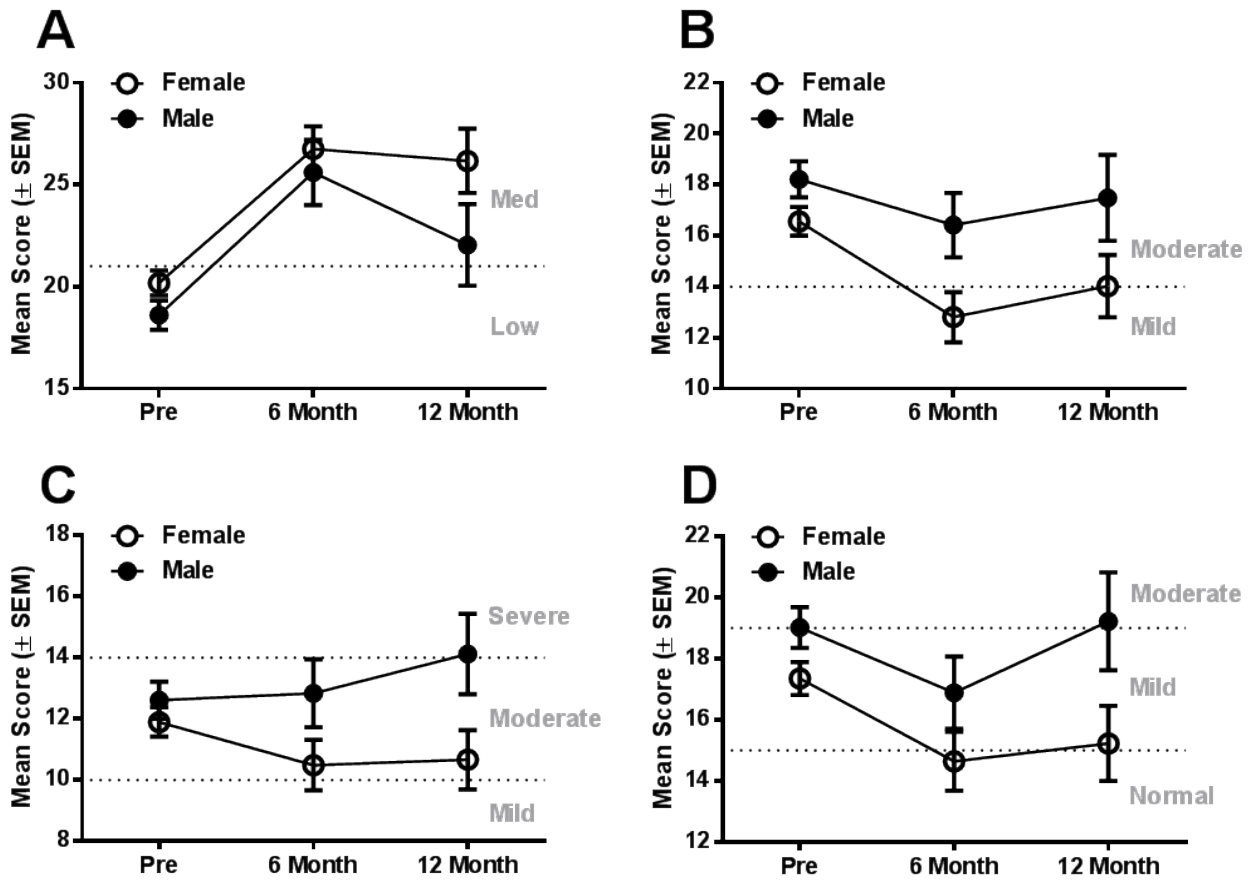

Figure 2. The mean ( \pm SEM) scores for males and females on PSEQ (A), DASS-21 depression (B), anxiety (C), and stress (D) subscales at initial assessment, 6- and 12-month follow-up. The categories of PSEQ and DASS-21 subscales are labeled in grey text and represented by dotted lines. *(A)-Pain Self-efficacy Questionnaire (PSEQ); (B)-DASS (Depression Scale); (C)-DASS (Anxiety Scale); (D) (Stress Scale).

Interestingly, we also found that these improvements in chronic pain intensity and pain self-efficacy were not translated into better psychological outcomes in depression, anxiety or stress. That is, pain-related outcomes (e.g., pain intensity, SF-36 bodily pain domains [BP]) showed significant improvements at 6 and 12 months, with a modest effect size of 0.8 - 0.85 . In contrast, there were only mild improvements observed on psychological measures such as depression and stress (effect size 0.16) at 6 months and these outcomes were not maintained at 12 months. The reason for the dissociation between pain improvement and lack of psychological change is unclear but may be suggestive of prevalence of some underlying psychiatric comorbidities in the chronic pain population, especially that of mood disorders [31]. The strength of relationship between chronic pain and mood disorder remains unclear. The role of drug and alcohol dependence with or without mood disorders cannot be underestimated [31] [32]. Importantly, as shown in this study, modest pain relief alone would not be sufficient to create a positive impact in the life of a patient with chronic pain but it nevertheless is an important step forward before patient motivated into more adaptive behaviours of accepting and self-managing their chronic pain condition. 
There were evidences for gender differences in the temporal course of these improvements with females showing greater improvement compared to males. The effects observed in pain and psychosocial outcomes between genders can be summarised in three key points. Firstly, both males and females showed improvements in pain related outcomes which were maintained at the 12 month follow-up. Secondly, females showed improvements in psychological functioning outcomes at 6 months whereas males did not. Lastly, there were short-term improvements in self-efficacy in both males and females at 6 months, but only females showed maintenance of improvements in self-efficacy at 12 months. In summary, these results suggest that females were more likely to sustain the benefits from multidisciplinary pain management treatment as seen in the improvements of pain related measures and self-efficacy.

There is mixed report in the literature on the gender differences observed in response to chronic pain treatment. Hampel et al. [33] found that both males and females showed short-term benefits of psychological intervention for those with chronic low back pain. In addition, they [33] found that improvements were maintained in females whereas males demonstrated negative treatment effect at a 12 month follow-up. In a randomized controlled multicenter trial, Jensen et al. [34] reported that a full-time multidisciplinary rehabilitation program produced substantial benefits in occupational outcome and was cost-effective up to 3 years in females with chronic back and neck pain but not in males. Negative outcomes for males have also been observed by Hooten et al. [19] for patients with fibromyalgia following multidisciplinary treatment in role physical, social functioning and general health perception compared with female counterparts. The current results are consistent with the observations that both genders show short-term psychosocial improvements but only females maintain these improvements. In contrast, de Rooij et al. [16] found that male gender predicted better outcomes from multidisciplinary treatment for chronic widespread pain.

Besides gender, this study showed the positive predictive relationship between chronic pain outcome and pain self-efficacy belief. Pain self-efficacy belief is an important psychological factor underpinning outcome as it mediates the relationship between pain-related fear and chronic pain [35] [36]. This is consistent with the current literature suggesting that self-efficacy is a predictor of treatment outcome for multidisciplinary pain management [35]. Poor pain self-efficacy is a surrogate marker for poor outcome. We recognize the patients with low self-efficacy may require more individualized cognitive and behavioural interventions before allocating the intensive pain group program. This further supports the importance of earlier and continuing cognitive behavioral therapy (CBT) in delineating and intervening psychological vulnerabilities, which maintain the maladaptive pain behaviours in selected group of chronic pain patient. These cognitive techniques could also be used for positive modeling, mastery experiences and social-reinforcement to improve readiness to change and psychological functioning.

This outcome study describes the characteristics of patients and their chronic pain referred to a tertiary hospital-based pain management center. The weakness of this large longitudinal survey was the low participation rate (30\% at 6 months and $20 \%$ at 12 months) to the questionnaires at the two follow-ups. For research purposes, response rate approximating of $60 \%$ is desirable [37]. Majority of patient with chronic pain referred to this center were often associated chronic refractory pain and complex psychosocial issues. However, our analysis showed that their baseline pain and psychosocial outcomes were not the cause of the non-participation bias, as no differences were detected between responders and non-responders with the baseline questionnaires. Unfortunately, other reasons for non-compliance or response bias were not explored further. In addition, this study was designed as a longitudinal cross-sectional study using patients as their own control. It was not intended to compare specific treatment responses, which would limit the general is ability of the treatment outcomes.

In comparison with our previous published survey on chronic pain demographic and its pain characteristics [4], we found that current cohort of chronic pain patients were slightly older (mean age of 58.6), had higher pain score (mean 7.1), lower pain self-efficacy (mean 19.7), and lower self-rated status of quality of life. Other pain center chronic low back pain populations also demonstrated better pain intensity and self-efficacy belief than this study cohort [38] [39]. General health issues in an older population of chronic pain patients may compound the self-management of chronic pain. Nicholas et al. [40] showed that in older chronic pain adults combining cognitive behavioral therapy based pain self-management and exercise was more effective than just the exercise alone.

Some would recognize chronic pain as an individualized disease with multiple dimensions and traditional biomedical treatment ascribed to chronic pain is often inadequate to address all of the problems related to chronic pain [41]. Some studies investigated chronic pain and found the distinct differences in the perception of 
pain and health related outcomes in different gender [42]-[44] or vulnerable socio-cultural patient groups [45] [46]. Efforts should be made in future to explore the relationship and interaction of individual perception of pain in their respective gender or socio-cultural groups may improve the outcomes of multidisciplinary pain management. Overall, this study found that male gender and low self-efficacy are associated with less sustainable outcomes. The identification of vulnerable patient subgroup supports more targeted and longer-term cognitive behavioral treatment. It is still early to decide a gender or socio-cultural specific treatment program is warranted. There are psychological concern of grouping the same vulnerable group of patient may not promote coping but rather learning and enhancing their maladaptive behaviours.

\section{Conclusion}

Individualized patient-centered multidisciplinary pain management remains an effective treatment for patients with chronic pain in both short (6-month) and long-term (12-month). There were clear pre- and post-treatment gender differences particularly in the psychological outcomes, suggesting that it may be beneficial to delineate and target vulnerable patient subgroups.

\section{Acknowledgements}

We would like to thank our department secretary Ms. Carol Parrey, ex-nursing unit manager Ms. Susie Kerr, and all the nursing staff who have contributed in administering, posting, collecting and entering all the outcomes data from 2004 to 2010 . We also like to acknowledge all the members in the multidisciplinary treatment team, particularly our late psychologists Mr. Tullio Citarrelli, physiotherapist Ms. Stephanie Mossman, psychologist Ms. Cate Courtney because without their constant dedication to the patients we would not be able to complete the whole research project.

\section{References}

[1] Blyth, F.M., March, L.M., Brnabic, A.J.M., Jorm, L.R., Williamson, M. and Cousins, M.J. (2001) Chronic Pain in Australia: A Prevalence Study. Pain, 89, 127-134. http://dx.doi.org/10.1016/S0304-3959(00)00355-9

[2] Blyth, F.M., March, L.M. and Cousins, M.J. (2003) Chronic Pain-Related Disability and Use of Analgesia and Health Services in a Sydney Community. Medical Journal of Australia, 179, 84-87.

[3] Blyth, F.M., March, L.M., Nicholas, M.K. and Cousins, M.J. (2003) Chronic Pain, Work Performance and Litigation. Pain, 103, 41-47. http://dx.doi.org/10.1016/S0304-3959(02)00380-9

[4] Kerr, S., Fairbrother, G. and Crawford, M. (2004) Patient Characteristics and Quality of Life among a Sample of Australian Chronic Pain Clinic Attendee. Internal Medical Journal, 34, 403-409. http://dx.doi.org/10.1111/j.1444-0903.2004.00627.x

[5] Jensen, M.P., Turner, J.A. and Romano, J.M. (2007) Changes after Multidisciplinary Pain Treatment in Patient Pain Beliefs and Coping Are Associated with Concurrent Changes in Patient Functioning. Pain, 131, 38-47. http://dx.doi.org/10.1016/j.pain.2006.12.007

[6] McCracken, L.M. and Zhao-Obrien, J. (2010) General Psychological Acceptance and Chronic Pain: There Is More to Accept than the Pain Itself. European Journal of Pain, 14, 170-175. http://dx.doi.org/10.1016/j.ejpain.2009.03.004

[7] Jensen, M.P., Nielson, W.R., Turner, J.A., Romano, J.M. and Hill, M.L. (2004) Changes in Readiness to Self-Manage Pain Are Associated with Improvement in Multidisciplinary Pain Treatment and Pain Coping. Pain, 111, 84-95. http://dx.doi.org/10.1016/j.pain.2004.06.003

[8] Flor, F., Fydrich, T. and Turk, D.C. (1992) Efficacy of Multidisciplinary Pain Treatment Centers: A Meta-Analytic Review. Pain, 49, 221-230. http://dx.doi.org/10.1016/0304-3959(92)90145-2

[9] Guzman, J., Esmail, R., Karjalainen, K., Malmivaara, A., Irvin, E. and Bombardier, C. (2001) Multidisciplinary Rehabilitation for Chronic Low Back Pain: Systematic Review. BMJ, 322, 1511-1516. http://dx.doi.org/10.1136/bmj.322.7301.1511

[10] Artner, J., Kurx, S., Cakir, B., Reichel, H. and Lattig, F. (2012) Intensive Interdisciplinary Outpatient Pain Management Program for Chronic Back Pain: A Pilot Study. Journal of Pain Research, 5, 209-216. http://dx.doi.org/10.2147/JPR.S31754

[11] Becker, N., Sjogren, P., Bech, P., Olsen, A.F. and Eriksen, J. (2000) Treatment Outcome of Chronic Non-Malignant Pain Patients Managed in a Danish Multidisciplinary Pain Center Compared to General Practice: A Randomized Controlled Trial. Pain, 84, 203-211. http://dx.doi.org/10.1016/S0304-3959(99)00209-2 
[12] Turk, D.C., Wilson, H.D. and Cahana, A. (2011) Treatment of Chronic Non-Cancer Pain. Lancet, 377, 2226-2235. http://dx.doi.org/10.1016/S0140-6736(11)60402-9

[13] McQuay, H.J., Eccleson, C., Morley, S. and de C Williams, A.C. (1997) Systematic Review of Outpatient Services for Chronic Pain Control. Health Technology Assessment, 1, 6.

[14] Dysvik, E., Kvaloy, J.T. and Natvig, G.K. (2012) The Effectiveness of an Improved Multidisciplinary Pain Management Programme: A 6- and 12-Month Follow-Up Study. Journal of Advanced Nursing, 68, 1061-1072. http://dx.doi.org/10.1111/j.1365-2648.2011.05810.x

[15] Baranoff, J., Hanrahan, S.J., Kapur, D. and Connor, J.P. (2013) Six Month Post-Treatment Deterioration in Acceptance (CPAQ-8) and Cognitions Following Multidisciplinary Pain Treatment. Journal of Behavior Medicine, Ahead of Print.

[16] de Rooij, A., van der Leeden, M. and Roorda, L.D. (2013) Predictors of Outcome of Multidisciplinary Treatment in Chronic Widespread Pain: An Observational Study. BMC Musculoskelet Disorder, 14, 133-144. http://dx.doi.org/10.1186/1471-2474-14-133

[17] Keogh, E., McCracken, L.M. and Eccleston, C. (2005) Do Men and Women Differ in Their Response to Interdisciplinary Chronic Pain Management. Pain, 114, 37-46. http://dx.doi.org/10.1016/j.pain.2004.12.009

[18] Skouen, J.S., Grasdal, A. and Haldorsen E.M.H. (2006) Return to Work after Comparing Outpatient Multidisciplinary Treatment Program versus Treatment in General Practice for Patients with Chronic Widespread Pain. European Journal of Pain, 10, 145-152. http://dx.doi.org/10.1016/j.ejpain.2005.02.005

[19] Hooten, W.M., Townsend, C.O. and Decker, P.A. (2007) Gender Differences among Patients with Fibromyalgia Undergoing Multidisciplinary Pain Rehabilitation. Pain Medicine, 8, 624-632. http://dx.doi.org/10.1111/j.1526-4637.2006.00202.x

[20] Bandura, A. (1977) Self-Efficacy: Toward a Unifying Theory of Behavioural Change. Psychological Review, 84, 191215. http://dx.doi.org/10.1037/0033-295X.84.2.191

[21] Nicholas, M.K. (1989) Self-Efficacy and Chronic Pain. Annual Conference of the British Psychological Society, St. Andrews.

[22] Nicholas, M.K. (2007) The Pain Self-Efficacy Questionnaires: Taking Pain into Account. European Journal of Pain, 11, 153-163. http://dx.doi.org/10.1016/j.ejpain.2005.12.008

[23] Keefe, F.J., Lefebvre, J.C., Maxiner, W., Salley, A.N. and Caldwell, D.S. (1997) Self-Efficacy for Arthritis Pain: Relationship to Perception of Thermal Laboratory Pain Stimuli. Arthritis \& Rheumatism, 10, 177-184. http://dx.doi.org/10.1002/art.1790100305

[24] Parkitny, L., McAuley, J.H., Walton, D., Pena Costa, L.O., Refshauge, K.M., Wand, B.M., Di Pestro, F. and Moseley, G.L. (2012) Rasch Analysis Supports the Use of the Depression, Anxiety, and Stress Scales to Measure Mood in Groups but Not in Individuals with Chronic Low Back Pain. Journal of Clinical Epidemiology, 65, 189-198. http://dx.doi.org/10.1016/j.jclinepi.2011.05.010

[25] Wood, B.M., Nicholas, M.K., Blyth, F., Asghari, A. and Gibson, S. (2010) The Utility of the Short Version of the Depression Anxiety Stress Scales (DASS-21) in Elderly Patients with Persistent Pain: Does Age Make a Difference? Pain Medicine, 11, 1780-1790. http://dx.doi.org/10.1111/j.1526-4637.2010.01005.x

[26] Shea, T.L., Tennant, A. and Pallant, J.F. (2009) Rasch Model Analysis of the Depression, Anxiety and Stress Scales (DASS). BMC Psychiatry, 9, 21. http://dx.doi.org/10.1186/1471-244X-9-21

[27] Okifuji, A., Turk, D.C. and Kalauoklani, D. (1999) Clinical Outcome and Economic Evaluation of Multidisciplinary Pain Centers. In: Block, A.R., Kramer, E.F. and Fernandez, E., Eds., Handbook of Pain Syndromes: Biopsychosocial Perspectives, Lawrence Erlbaum Associates, Mahwah, 77-97.

[28] Cohen, J. (1983) Statistical Power Analysis for the Behavioural Sciences. 2nd Edition, Lawrence Erlbaum Associates, Hillsdale.

[29] Cnaan, A., Laird, N.M. and Slasor, P. (1997) Using the General Linear Mixed Model to Analyse Unbalanced Repeated Measures and Longitudinal Data. Statistics in Medicine, 16, 2349-2380. http://dx.doi.org/10.1002/(SICI)1097-0258(19971030)16:20<2349::AID-SIM667>3.0.CO;2-E

[30] Krueger, C. and Tian, L. (2004) A Comparison of the General Linear Mixed Model and Repeated Measures ANOVA Using a Dataset with Multiple Missing Data Points. Biological Research for Nursing, 6, 151-157. http://dx.doi.org/10.1177/1099800404267682

[31] Arnow, B.A., Hunkeler, E.M., Blasey, C.M., Lee, J., Constantino, M.J., Firemen, B., Kraemer, H., Dea, R., Robinson, R. and Hayward, C. (2006) Comorbid Depression, Chronic Pain, and Disability in Primary Care. Psychosomatic Medicine, 68, 262-268. http://dx.doi.org/10.1097/01.psy.0000204851.15499.fc

[32] Cheatle, M. (2011) Depression, Chronic Pain, and Suicide by Overdose: On the Edge. Pain Medicine, 12, S43-S48. http://dx.doi.org/10.1111/j.1526-4637.2011.01131.x 
[33] Hampel, P., Graef, T., Krohn-Grimberghe, B. and Tlach, L. (2009) Effects of Gender and Cognitive-Behavioral Management of Depressive Symptoms on Rehabilitation Outcome among Inpatient Orthopaedic Patients with Chronic Low Back Pain: A 1 Year Longitudinal Study. European Spine Journal, 18, 1867-1880. http://dx.doi.org/10.1007/s00586-009-1080-z

[34] Jensen, I.B., Bergstrom, G., Ljungquist, T. and Bodin, L. (2005) A 3-Year Follow-Up of a Multidisciplinary Rehabilitation Programme for Back and Neck Pain. Pain, 115, 273-283. http://dx.doi.org/10.1007/s00586-009-1080-z.

[35] Meredith, P., Strong, J. and Feeney, J.A. (2006) Adult Attachment, Anxiety and Pain Self-Efficacy as Predictors of Pain Intensity and Disability. Pain, 123, 1-2, 146-154.

[36] Woby, S.R., Urmston, M. and Watson, P.J. (2007) Self-Efficacy Mediates the Relation between Pain-Related Fear and Outcome in Chronic Low Back Pain Patients. European Journal of Pain, 11, 71-78.

[37] Fincham, J.E. (2008) Response Rate and Responsiveness for Surveys, Standards, and the Journal. American Journal of Pharmaceutical Education, 72, 43.

[38] Flavell, H.A., Carrafa, G.P., Thomas, C.H. and Disler, P.B. (1996) Managing Chronic Back Pain: Impact If an Interdisciplinary Team Approach. Medical Journal of Australia, 165, 253-255.

[39] Van Hoff, M.L., Van der Merwe, J.D., O’Dowd, J., Pavlov, P.W., Spruit, M., De Kleuver, M. and Van Limbeek, J. (2010) Daily Functioning and Self-Management in Patient with Chronic Low Back Pain after an Intensive Cognitive Behavioural Programme for Pain Management. European Spine Journal, 19, 1517-1526. http://dx.doi.org/10.1007/s00586-010-1435-5

[40] Nicholas, M.K., Asghari, A., Blyth, F.M., et al. (2013) Self-Management Intervention for Chronic Pain in Older Adults: A Randomised Controlled trial. Pain, 154, 824-835. http://dx.doi.org/10.1016/j.pain.2013.02.009

[41] Schatman, M.E. (2011) Psychological Assessment of Maldynic Pain: The Need for a Phenomenological Approach. In: Giordano, J., Ed., Maldynia: Inter-Disciplinary Perspective on the Illness of Chronic Pain, CRC Press, New York, 157-182.

[42] Edwards, R.R., Doleys, D.M., Lowery, D. and Fillingim, R.B. (2003) Pain Tolerance as a Predictor of Outcome Following Multidisciplinary Treatment for Chronic Pain: Differential Effects as a Function of Sex. Pain, 106, 419-426. http://dx.doi.org/10.1016/j.pain.2003.09.004

[43] Sheffield, D., Biles, P.L., Orom, H., Maixner, W. and Sheps, D.S. (2000) Race and Sex Differences in Cutaneous Pain Perception. Psychosomatic Medicine, 62, 517-523.

[44] Edwards, R., Augustson E.M. and Fillingim, R. (2000) Sex Specific Effects of Pain Related Anxiety on Adjustment to Chronic Pain. Clinical Journal of Pain, 16, 46-53. http://dx.doi.org/10.1097/00002508-200003000-00008

[45] Merry, B., Edwards, R.R., Buenaver, L.F., McGuire, L., Haythornthwaite, J.A., Doleys, D.M. and Campbell, C.M. (2011) Ethnic Group Differences in Outcomes of Multidisciplinary Pain Treatment. Journal of Musculoskeletal Pain, 19, 24-30. http://dx.doi.org/10.3109/10582452.2010.538821

[46] Green, C.R., Anderson, K.O., Baker, T.A., Campbell, L.C., Decker, S., Fillingim R.B, Kaloukalani, D.A., Lasch, K.E., Myers, C., Tait, R.C., Todd, K.H. and Vallerand, A.H. (2003) The Unequal Burden of Pain: Confronting Racial and Ethnic Disparities in Pain. Pain Medicine, 4, 277-294. http://dx.doi.org/10.1046/j.1526-4637.2003.03034.x 